\title{
The Fever: How Malaria Has Ruled Humankind for 500,000 Years
}

\author{
S. Shah \\ New York, NY: Sarah Crichton Books, 2010, 320 pages, \$26
}

Throughout human history, mankind has dealt with many deadly diseases. Although historians often focus on highly lethal diseases, such as smallpox, measles, and the plague, malaria has been equally devastating. This evasive adversary has afflicted humanity since the beginning of civilization and even in modern days. Among its victims were Julius Caesar, Dante, Lord Byron, Oliver Cromwell, and Theodore Roosevelt. Despite our knowledge obtained through years of prevention and local eradication, malaria still affects millions around the world. In The Fever: How Malaria Has Ruled Humankind for 500,000 Years, Sonia Shah chronicles this ancient and modern interaction between humanity and malaria.

As a journalist, Sonia Shah captures firsthand events in developing countries around the world where the Plasmodium bacteria manage to proliferate near major cities. In the opening pages, she talks about a small town called Chepo, located "just two hours away from a boisterous international center of commerce, Panama City." Chepo is inhabited by a community of indigenous people with little communication to the modern world. This lack of connection has created an obstacle for local authorities to educate the local population about efforts to control the Plasmodium habitats. Failure in this aspect has lead to outbreaks of malaria that subsequently have spread to nearby cities.

In her attempt to deliver an account about Plasmodium's origins and evolution, Ms. Shah uses a simple style. Rather than providing excessive scientific details, she narrates the development of Plasmodium from the time it infects its first host, the Anopheles mosquito, to the time it attacks its end target, humans, birds, and other animals. She describes the evolution of the Plasmodium bacteria from an autotrophic ancestor capable of photosynthesis to its modern bacterial form. Often she includes visual aids to better explain the structure of the parasite and its rather complex life cycle.

Something that we found surprising was the author's description of the influential part malaria played in the political and economic history of the world. In particular, as the

COPYRIGHT @ 2012 by the Society of Nuclear Medicine, Inc.

Published online Dec. 12, 2011.

DOI: 10.2967/jnumed.111.097527
European empires expanded their territories to the New World, they encountered new lethal bacteria responsible for causing diseases among them, in particular Plasmodium. In the New World, colonists viewed African people as crucial in the exploitation of resources and wealth from newly colonized regions because of their resistance to malaria. Africans had previously developed immunities to fight malaria because of their Duffy gene. This acquired immunity enabled them to live with the parasite and, if infected, experience only a discomforting fever. European colonists-unfortunately for them-often perished when bitten by a malaria-infested mosquito. The colonists saw the immunologic advantage of the African and so saw slavery as a necessity since no other human was more suited to withstand the serious consequences of being exposed to the parasite.

The author introduces us to various people living in regions of the world affected by malaria. She captures the thoughts of these individuals and depicts a vivid picture of the situation, which in turn offers us better understanding of the problem. Ms. Shah even presents contrasting ideologies by highlighting a nontraditional view expressed by a reporter at an international conference on malaria held in Cameroon, who stated that living with the Plasmodium bacteria has been mostly positive, since by natural selection it makes people stronger.

One provocative idea the author asserts is that perhaps developed countries do not know how to properly approach a disease as complex as malaria. Ms. Shah makes a case that struggling local scientists, not affluent high-tech laboratories, are making the most significant impact in those areas. According to her, the real progress has been performed by "obscure, underfinanced scientists making breakthroughs that go all but ignored." The contrast was evident in the early race to find the life process and cell structure of malaria during the late 19th century. In the modern era, this is typified by the well-funded Harvard Malaria Institute in the United States, where there are relatively few cases of malaria, whereas entities such as the Gorgas Institute of Malaria in Panama, where malaria is endemic, has only scarce resources.

Overall, The Fever: How Malaria Has Ruled Humankind for 500,000 Years is a well-written, insightful book about a disease that has been with us for thousands of years. In 
her book, Sonia Shah provides us a unique perspective about those living day to day with the parasite. We recommend this book for anyone in the health-care field interested in learning about health-care epidemiology, political healthcare policy, and medical technologic advances of this deadly disease.
Carlos J. Carcamo

Robert Matthews*

*Stony Brook University Medical Center

Department of Radiology

Health Sciences Center, Level 4, Room 120

Stony Brook, NY 11794-8460

E-mail: robert.matthews@stonybrook.edu 